\title{
Merit goods and excise taxation in quasilinear markets for complementary private consumption
}

GERASIMOS T. SOLDATOS, Dr.*

\section{Article**}

JEL: H21, H44, H50, D01, E02

https://doi.org/10.3326/pse.44.4.6

\footnotetext{
* The constructive reviewing of this paper is gratefully acknowledged.

${ }^{* *}$ Received: February 6, 2020

Accepted: August 20, 2020
}

Gerasimos T. SOLDATOS

American University of Athens, Athens, Greece; Emeritus Pindarou 43, 56224 Thessaloniki, Greece

e-mail: soldgera@yahoo.com

ORCiD: 0000-0002-5615-2738 


\section{Abstract}

This paper models merit goods such as education and health, in a Lindahl-Foley environment in which public goods may be treated as private ones since merit goods are public goods that could have been provided privately. It does so in terms of a Levitan-Shubik quasilinear quadratic utility from complementary commodities and uniform taxation of non-merit commodities to finance the provision of merit goods. This analytical framework serves best the purpose of characterizing the general equilibrium. Complementarity is found to serve as an engine for increased output after the introduction of taxation, with a higher volume of private goods, lower tax rate, and minimal price for the merit goods at the new equilibrium.

Keywords: merit goods, complementarity, quasilinear quadratic utility, excise taxation

\section{INTRODUCTION}

Although there is a debate concerning the content of the term "merit goods" (Desmarais-Tremblay, 2017; 2019), the standard practice is to relate such goods to healthcare, education, and social protection spending, which are rival in private consumption and affect welfare through distribution policies; public goods like defense, are mostly non-rival in nature (Fiorito and Kollintzas, 2004). The firstbest strategy in providing merit goods is to those who need them after their identification, and this identification may be too costly to be administered. The second-best strategy involves the taxation of non-merit goods that can substitute for the merit good, like TV vs. education, and subsidization of non-merit goods that can complement the merit good, like grocery and food for the poor (Schroyen, 2005; Wenzel and Wiegard, 2006). In any case, merit goods are those goods and services that low-income households will under-consume if acquired on the basis of ability to pay, but which ought to be provided to these people by the public authorities. This "ought" is taken to be in violation of consumer sovereignty and hence, constitutes (soft) paternalism that does not fit the standard welfare economics framework (Cserne and Desmarais-Tremblay, 2018). However, there do exist attempts to model merit goods in the context of taxation (Schroyen, 2005; Levaggi and Menoncin, 2008).

The empirical evidence is that merit goods are complements to private consumption, which is not the case for public goods and hence the positive effects of merit goods on the economy exceed those of public goods (Fiorito and Kollintzas, 2004; Kotera and Sakai, 2017). This evidence confers real-world relevance on the theoretical argument that there is scope for complementarity between private and public goods (Kaufman, 1998); it just sorts out which exactly are the public that are complementary to private goods. But, from this point of view, the provision of merit goods can be considered neither paternalistic nor incompatible with willingness to pay, falling outside the realm of Pareto efficiency. People treat merit goods as complementary to their overall consumption when maximizing utility. Given in general the positive externality of merit goods, the state might address this 
problem by financing the production of them from the proceeds of a tax on private consumption.

Assuming away considerations of saving, private consumption coincides with income before the introduction of merit goods. It could be represented by one consumer good in pre-tax utility, which utility nevertheless contains an argument applying to a would-be merit good too. Responsible for the satisfaction of the demand for the would-be commodity is government production, which is available to the consumer once demand for it is expressed. The production is made possible on the basis of taxation. The debate here is whether the tax should involve (i) a combination of income taxation and commodity taxation below the level of only a Pigovian tax or (ii) only "corrective" Pigovian taxation. It is a question motivated by environmental concerns but generalized to include any public good, posed because each choice results in the provision of different levels of public good (Chang, 2000).

Of course, the meaning of "corrective" under complementarity in a two-good framework, is tax income able to subsidize the production of the good with the positive externality. This is the only way to finance the production of a merit good but only if this good does not already exist in the economy; the income tax is also a tax on the consumption commodity. If merit goods already exist, the income tax is also a tax on these goods to subsidize their production (Schroyen, 2005). Consequently, in this case, only commodity taxation on the private good may be used to finance merit-good provision. The general conclusion is that indirect taxation on non-merit goods is the means through which governments can in practice, regardless of the issue of pre-existence, supply merit goods. This is a conclusion applying to more than one private good, in which case only some substitutes for the merit good might be taxed, as the second-best strategy above prescribes. In any case, as soon as there is no dilemma about commodity tax alone or in combination with income tax, only one will be the level of merit-good provision.

Now, considering a merit good and a non-merit complementary consumption commodity, divided perhaps into a complementary and another complementary too, or substitute good, one in essence considers the whole economy. Comparative statics, then, such as those surrounding the "double dividend" controversy in environmental economics, have in our case a flavor of macro-dynamics too. This is especially so when the origin of the discussion is the pre-merit goods pre-tax status quo towards a new equilibrium that includes such goods, as follows: If the value of the volume of merit goods produced by the state is the one that consumers would prefer, the tax adjusts accordingly, and consumers absorb the value of the merit goods they wanted. Under conditions of private-public good complementarity, they will also want to increase the consumption of private goods to at least its pre-tax level, which is not possible under the after-tax income. The associated excess demand will induce a price increase that will in turn encourage the supply of more private goods. 
By Walras's law, the value but not quantity of merit goods will decrease, which beyond ethics, is the economic reason why such goods should be offered at a minimal price: the private goods price increase will be smaller after the imposition of taxation, and their production larger. At the after-tax equilibrium, the volume of merit goods will be the one desired by the consumer, with increased volume of private-consumption goods and subsequently, a lower tax rate: Supply creates its own demand, after all. Much more so, under a sales or specific tax, which firms pass on to the consumer only partially. Such in a general viewpoint does not presume a framework of Lindahl-Pareto equilibrium workings, but does hypothesize a Lindahl-Foley environment in which public goods may be treated as private ones. The structure of public goods is the linear one presupposed by Lindahl so that preferences about such goods can be subject to the dictum that "more is preferable to less".

This is what is assumed by the next section too, but within the context of a quasilinear quadratic utility, implying that there does exist ultimately some point of satiation at which the utility from complementarity is exhausted. Three goods are assumed; one is the merit good, another one is a private good, which is strongly complementary to the merit good, and the third one represents other private consumption, whose complementarity may be weaker. The intensity of complementarity is a way of motivating the distinction among the three goods, since one only complementarity index can be used by the utility function under consideration. The merit good may be public education, with school supplies being the strongly complementary one; this is a case relevant in terms of expenses to younger households. Or, the merit good may be public health promotion, with the strongly complementary product being the unavoidable services from the private health system, a case which is more relevant to older households ${ }^{1}$. Accordingly, the assumption made about the presence of the bliss point in utility is reasonable. There is a point beyond which further education and purchase of school supplies or benefit from public and private health services, becomes meaningless; utility remains unchanged. In any case, judging from human development reports (Groot and van den Brink, 2006), the complementarity of the merit good with private consumption may be strong, too.

The quantity supplied of this good is assumed to be the one coming out of the utility maximization problem à la Foley (1970; Florenzano and del Mercato, 2006) approach. It is produced by one public firm, financed either through an ad valorem tax or via a specific tax on the two private-sector commodities. The consumption of merit goods made possible by taxing complementary products will encourage the consumption of the taxed products as well. The tax rates are found to depend only on the supply of the merit good and the size of the public firm relative to the size of each of the two private firms. Calibrations suggest that ad valorem taxation is more

\footnotetext{
${ }^{1}$ There are many reasons why public education should be provided: the classical efficiency argument, but also from a distributive point of view this could be defended. Then the question is: how is the merit good argument for public education built further?
} 
flexible and less antagonizing of the private sector firms relative to revenue neutral specific taxation under consumer sovereignty, but the latter type of excise taxation is more precise in terms of optimality, fostering production efficiency as well. Given additionally the efficiency under which the public firm is supposed to operate, specific taxation is compatible with overall Pareto efficiency by comparison to $\mathrm{ad}$ valorem taxation. Section 3 concludes this paper by comparing the approach adopted here and its results with similar work. The main novelty in approach is, of course, the choice to analyze the subject in a Lindahl-Foley-type of framework under quasilinear quadratic utility. The main novelty in terms of results is that in so far as the financing of merit goods is concerned, only an institutional preference for private sector might justify the choice of a sales tax as a financing means.

\section{FORMAL CONSIDERATIONS}

Consider two complementary groups of products, $q_{i}, i=1,2$, being sold each at an average price of $p_{i}$. There is also a non-profit public firm, providing at price $p_{s}$ another good, $q_{s}$, which is complementary to $q_{i}$ and $q_{j}, j=1,2, j \neq i$. It does so by collecting either an ad valorem tax or a specific tax imposed on the firms of the private goods at rates $t$ and $\tau$, respectively. That is, if $\pi_{s}$ denotes profit for the public firm,

$$
\begin{aligned}
& \pi_{s}=p_{s} q_{s}-c_{s} q_{s}=p_{s} q_{s}-t\left(p_{1} q_{1}+p_{2} q_{2}\right)=0 \Rightarrow \\
& t\left(p_{1} q_{1}+p_{2} q_{2}\right)=p_{s} q_{s}
\end{aligned}
$$

where $c_{s}$ is the average and marginal production cost of $q_{s}$. Similarly,

$$
\tau\left(q_{1}+q_{2}\right)=p_{s} q_{s}
$$

That is, indirect taxation is supposed to be revenue neutral, and the public-firm budget is balanced in line with Pareto efficiency requirements, given truthful revelation if preferences; presumably, $p_{s}=c_{s}$.

The quantity of the public good produced is the one which is desired by the consumer, who is assumed to behave in line with Levitan and Shubik's (Shubik and Levitan, 1980; Choné and Linnemer, 2019) non-symmetric quasilinear quadratic utility model (QQUM) ${ }^{1}$, maximizing,

$$
\begin{aligned}
& U\left(q_{1}, q_{2}, q_{s}\right)-\sum_{i=1}^{2} p_{i} q_{i}-p_{s} q_{s} \\
& =\sum_{i=1}^{2}\left(a_{i}-p_{i}\right) q_{i}+\left(a_{s}-p_{s}\right) q_{s}-\frac{\sigma}{\beta}\left(q_{1} q_{2}+q_{1} q_{s}+q_{2} q_{s}\right) \\
& -\frac{1}{2 \beta}\left\{\sum_{i=1}^{2} \frac{\left[1-\sigma\left(1-\omega_{i}\right)\right]}{\omega_{i}} q_{i}^{2}+\frac{\left[1-\sigma\left(1-\omega_{s}\right)\right]}{\omega_{s}} q_{s}^{2}\right\}
\end{aligned}
$$


where $\sigma \in(-\infty, 0)$ captures the extent of complementarity between $q_{i}$ and $q_{j}$, and between $q_{i}$ and $q_{s}$, on the average, because the complementarity between the two private goods may differ from that between these goods and the merit one. Parameter $\omega \in(0,1)$ is a weight reflecting the size of each firm, $\omega_{1}+\omega_{2}+\omega_{s}=1$. Consumers take the $\omega$ 's for granted. But, from the comparative statics viewpoint, the variations of $\omega_{s}$ reflect variations of the size of this firm that do not necessarily reflect public-firm output variations in the same direction. A similar argument is applicable to private firms, with the observation that an increase, say, of $\omega_{s}$, implies a decrease of the sum $\left(\omega_{1}+\omega_{2}\right)$, but not necessarily of private firms' output given that all products are complementary.

Coefficient $a>0$ measures quality; it is a (marginal) quality (or utility) index, one for each variety $i$, and $s$ ): Other things equal, an increase in increases the marginal utility of consuming the good to which it refers. $\beta>0$ shows how quickly the marginal utility of each good declines; it is a concavity parameter: Letting the lefthand side of (3) be noted by $\Gamma, \partial^{2} \Gamma / \partial q^{2}=[1-\sigma(1-\omega)] / \beta \omega$. It is a very important parameter, because zeroing the total differential of this derivative for a given $\sigma$, one obtains: $d \omega / d \beta=-\omega[1-\sigma(1-\omega)] / \beta(1-\sigma)<0$, which indicates that an increase of the slope of the marginal utility curve decreases the size of the firm to which the differential refers. The steepness of the marginal utility presumably shapes the extent of complementarity as sellers provide the kinds of goods consumers prefer: Zeroing again the total differential, and setting $d \omega=0$, yields: $d \sigma / d \beta=-[1-\sigma(1-\omega)] / \beta(1-\omega)<0$; the higher the slope of the marginal utility curve, the weaker the complementarity is. These, of course, are trends expected to be qualified considerably by the introduction of taxation.

The indirect demand functions obtained from (3) are:

$$
p_{i}=\frac{\beta \omega_{i} a_{i}-\sigma \omega_{i}\left(q_{j}+q_{s}\right)-\left[1-\sigma\left(1-\omega_{s}\right)\right] q_{i}}{\beta \omega_{i}}
$$

and

$$
p_{s}=\frac{\beta \omega_{s} a_{s}-\sigma \omega_{s}\left(q_{1}+q_{2}\right)-\left[1-\sigma\left(1-\omega_{s}\right)\right] q_{s}}{\beta \omega_{s}}=c_{s}
$$

If the public sector respects supposed consumer sovereignty regardless of the market structure considerations surrounding the supply of private goods, the case with the specific tax will be in view of (5) and given (2):

$$
p_{s} q_{s}=\frac{\beta \omega_{s} a_{s} q_{s}-\sigma \omega_{s}\left(q_{1}+q_{2}\right) q_{s}-\left[1-\sigma\left(1-\omega_{s}\right)\right] q_{s}^{2}}{\beta \omega_{s}}
$$

or inserting from (2), $\left(q_{1}+q_{2}\right)=p_{s} q_{s} / \tau$ in the right-hand side of (6), 


$$
p_{s} q_{s}=\frac{\tau \beta \omega_{s} a_{s} q_{s}-\sigma \omega_{s} p_{s} q_{s}^{2}-\tau\left[1-\sigma\left(1-\omega_{s}\right)\right] q_{s}^{2}}{\tau \beta \omega_{s}}
$$

from which, solving for $\tau$, yields:

$$
\tau=\frac{\sigma \omega_{s} q_{s}}{\left[\beta \omega_{s} a_{s} q_{s}-\beta \omega_{s}-\left[1-\sigma\left(1-\omega_{s}\right)\right] q_{s}^{2}\right]}
$$

Also, obtaining the sum $\left(p_{1} q_{1}+p_{2} q_{2}\right)$ from (4) by multiplication with the corresponding $q_{i}$, and solving for $t$, yields:

$$
t=\frac{\beta^{2} \omega_{1} \omega_{2} \omega_{s} a_{s} q_{s}-\sigma \beta \omega_{1} \omega_{2} \omega_{s}\left(q_{1}+q_{2}\right) q_{s}-\beta \omega_{1} \omega_{2}\left[1-\sigma\left(1-\omega_{s}\right)\right] q_{s}^{2}}{\left\{\beta^{2} \omega_{1} \omega_{2} \omega_{s}\left(a_{1} q_{1}-a_{2} q_{2}\right)-\sigma \beta \omega_{1} \omega_{2} \omega_{s}\left[\left(q_{2}+q_{s}\right) q_{1}+\left(q_{1}+q_{s}\right) q_{2}\right]-\beta \omega_{s}\left[1-\sigma\left(1-\omega_{s}\right)\right]\left(\omega_{1}+\omega_{2}\right)\right\}}
$$

Although $\tau$ is independent of private sector circumstances, this does not appear to be true for $t$, because it depends on the production volume of the private goods. Nevertheless, there does exist a simple relationship between the two tax rates, which is obtained by noting that (7) becomes in view of (1):

$$
\begin{gathered}
t\left(p_{1} q_{1}+p_{2} q_{2}\right)=\frac{\tau \beta \omega_{s} a_{s} q_{s}-\sigma \omega_{s} t\left(p_{1} q_{1}+p_{2} q_{2}\right) q_{i}-\tau\left[1-\sigma\left(1-\omega_{s}\right)\right] q_{s}^{2}}{\tau \beta \omega_{s}} \Rightarrow \\
t=\frac{\tau\left\{\beta \omega_{s} a_{s} q_{s}-\left[1-\sigma\left(1-\omega_{s}\right)\right] q_{s}^{2}\right\}}{\omega_{s}\left(p_{1} q_{1}+p_{2} q_{2}\right)\left(\tau \beta+\sigma q_{s}\right)}
\end{gathered}
$$

(9) is as independent of private sector considerations as (8) is. Moreover, it is susceptible to calibration under the same assumptions surrounding (8) for various $\tau$ 's and values of the sum: $\left(p_{1} q_{1}+p_{2} q_{2}\right)$, which is not the case with the more complex expression regarding $t$ above. The calibrations, of course, are a means of illustrating the overall picture resulting from the interaction of the partial derivatives of comparative statics; an interaction whose outcome might be difficult to appreciate intuitively on the basis only of algebra.

The calibration assumptions about (8), derive from the complementarity between the public and private goods, rendering the numerator of (8) negative. Since the fraction has to be positive, the denominator has to be negative, or:

$$
\begin{gathered}
{\left[1-\sigma\left(1-\omega_{s}\right)\right] q_{s}^{2}-\beta \omega_{s} a_{s} q_{s}+\beta \omega_{s}>0 \Rightarrow} \\
q_{s}=\frac{\beta \omega_{s} a_{s} \pm \sqrt{\left(\beta \omega_{s} a_{s}\right)^{2}-4 \beta \omega_{s}\left[1-\sigma\left(1-\omega_{s}\right)\right]}}{2\left[1-\sigma\left(1-\omega_{s}\right)\right]}>0
\end{gathered}
$$

The discriminant, $\Delta$, will be positive iff: 


$$
\begin{gathered}
\Delta=\left(\beta \omega_{s} a_{s}\right)^{2}-4 \beta \omega_{s}\left[1-\sigma\left(1-\omega_{s}\right)\right]>0 \Rightarrow \beta \omega_{s} a_{s}^{2}>4\left[1-\sigma\left(1-\omega_{s}\right)\right] \Rightarrow \\
\beta \omega_{s} a_{s}^{2}-4 \sigma \omega_{s}>4(1-\sigma) \Rightarrow \omega_{s}>\frac{4(1-\sigma)}{\beta a_{s}^{2}-4 \sigma}
\end{gathered}
$$

and since:

$$
1>\omega_{s}>\frac{4(1-\sigma)}{\beta a_{s}^{2}-4 \sigma} \Rightarrow \beta a_{s}^{2}-4 \sigma>4-4 \sigma \Rightarrow \beta>\frac{4}{a_{s}^{2}}
$$

This relationship between $\beta$ and $a_{s}$ is illustrated in Fig. 1 , where, for example, $\beta \approx 5$ when $a_{s}=1$ :

\section{Figure 1}

$f(x) \equiv \beta, x \equiv a_{s}, \beta \equiv 4 / a_{s}^{2}$

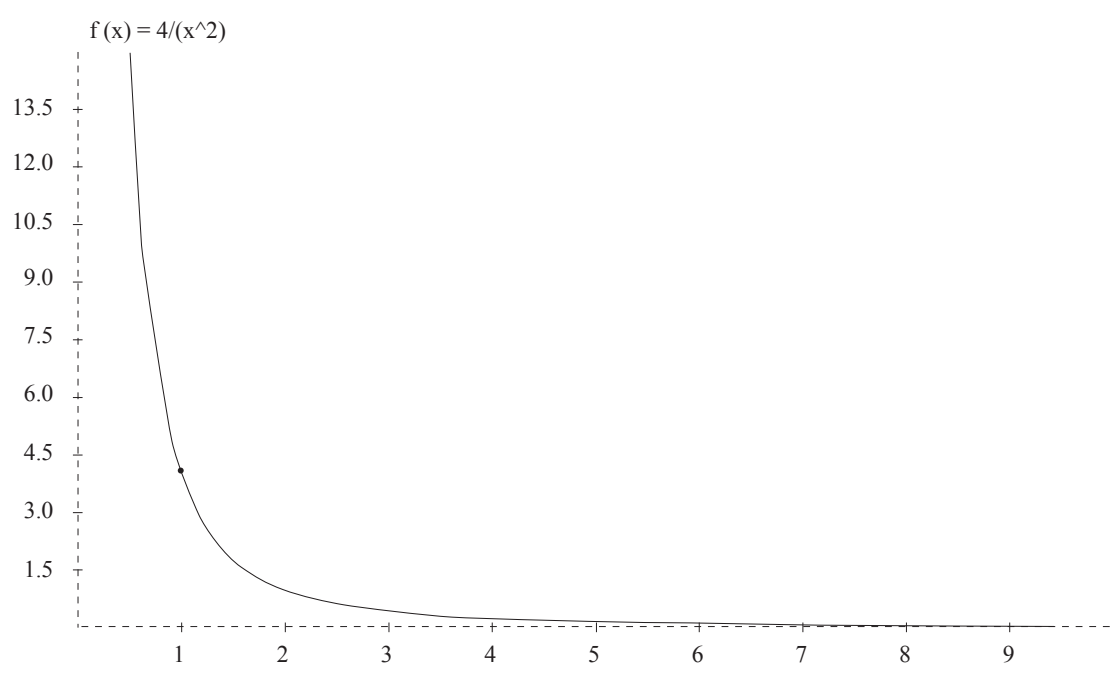

The highest value $a_{s}$ can take on is around 9 while it appears that it tends to zero as $\beta$ tends to infinity; indeed, the marginal utility from the public good and the slope of the marginal utility curve are inversely related by definition. Calibrations should reflect this relationship, given that both solutions described by (10) are acceptable. The numerator of the solution with the negative square root, is positive because:

$$
\left(\beta \omega_{s} a_{s}\right)^{2}>\left(\beta \omega_{s} a_{s}\right)^{2}-4 \beta \omega_{s}\left[1-\sigma\left(1-\omega_{s}\right)\right] \Rightarrow 0>-4 \beta \omega_{s}\left[1-\sigma\left(1-\omega_{s}\right)\right]
$$

which is true. Also, positive will be the numerator in the case of the positive square root, since:

$$
\left(\beta \omega_{s} a_{s}\right)^{2}>2 \beta \omega_{s}\left[1-\sigma\left(1-\omega_{s}\right)\right] \Rightarrow \beta \omega_{s} a_{s}^{2}>2\left[1-\sigma\left(1-\omega_{s}\right)\right]
$$


which is true, because $\Delta>0$ if: $\beta \omega_{s} a_{s}^{2}>4\left[1-\sigma\left(1-\omega_{s}\right)\right]$, which implies that $\beta \omega_{s} a_{s}^{2}>2\left[1-\sigma\left(1-\omega_{s}\right)\right]$ as well. In sum, both solutions in (10) are acceptable, given that their denominator is positive too.

Now, letting $z \equiv \tau, \omega_{s} \equiv x \in(0,1)$, and $y \equiv q_{s} \in(0,10)$, we obtain the following simulations of (8) through wolframalpha.com:

Figure 2(A)

$\tau$ under: $\beta=15, a=0.5, \sigma=-0.5$

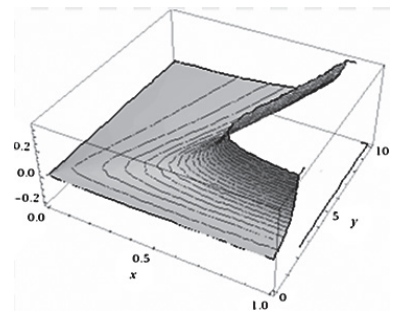

\section{Figure 3(A)}

$\tau$ under: $\beta=15, a=0.5, \sigma=-1$

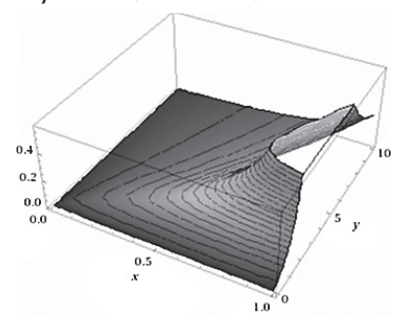

Figure 2(в)

$\tau$ under: $\beta=2, a=2, \sigma=-0.5$

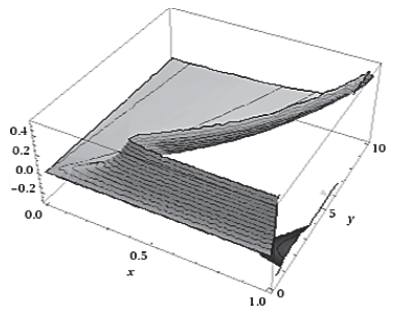

Figure 3(в)

$\tau$ under: $\beta=2, a=2, \sigma=-1$

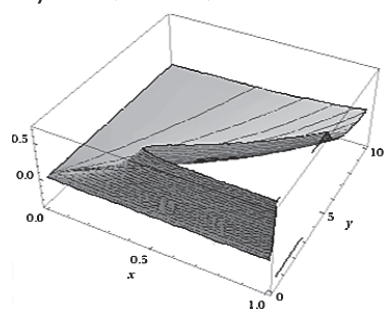

Note at first that experimentations with the scale of were found to change only the scale of axis. Note also that in all four diagrams there is a ridge running from the origin of the three axes to some maximum value of the specific-tax rate, which is the highest the calibrations can give. The points along the ridge reflect the optimal combinations among tax rate, public firm size, and public sector output. They comprise a stable locus. Contrasting the figures based on a steep marginal utility curve on the left, with those on the right where this slope is much smaller, one concludes that the optimal size of the state firm and of its output increase as the slope becomes larger. The tax rate becomes smaller, because the output of the private complementary goods increases, too. The intuition here is that the faster the rate at which one unit of the merit good provides its utility, the more units of this good have to be provided in order to satisfy demand once there is no option of subsidized non-merit goods. Also, comparing the diagrams on the top with those at the bottom, one infers that these increases in public sector magnitudes become greater as complementarity becomes stronger, with the difference becoming smaller as the slope of marginal utility curve becomes smaller, too. The stronger the complementarities in the eyes of the consumer, the more the public firm and by complementarity, the private firms have to produce. Moreover, in all four figures, any attempt to increase output (size) 
away from the locus, will increase size (output) unless $\tau$ is reduced, limiting the expansion of both, with the reduction of $\tau$ being larger when complementarity is stronger. That is, any movement away from the locus will destroy the market of nonmerit goods. These conclusions are crosschecked mathematically in the Appendix.

Next, $t \equiv z$ is simulated based on (10) and under: $x \in(0,1), y \in(0,10)$ again, and $\beta=2, a=2, \sigma=-1$ :

\section{FiguRe 4(A)}

t under: $\left(p_{1} q_{1}+p_{2} q_{2}\right)=40, \tau=0.1$

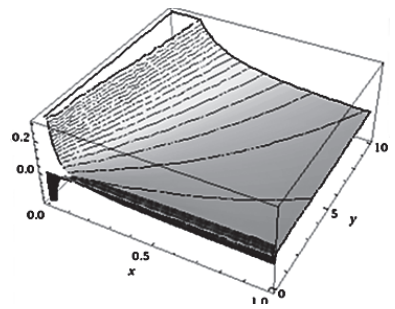

\section{FiguRE 5(A)}

t under: $\left(p_{1} q_{1}+p_{2} q_{2}\right)=40, \tau=0.2$

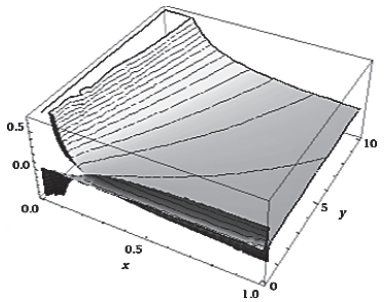

Figure 6(A)

t under: $\left(p_{1} q_{1}+p_{2} q_{2}\right)=40, \tau=0.3$

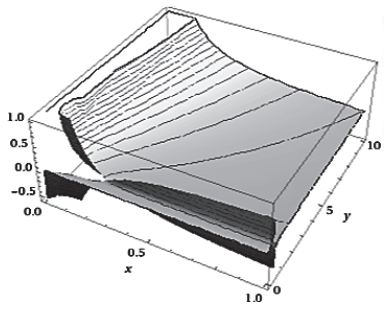

FiguRe 4(B)

t under: $\left(p_{1} q_{1}+p_{2} q_{2}\right)=80, \tau=0.1$

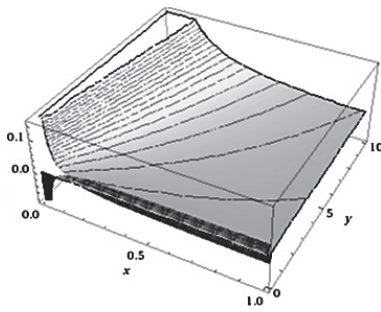

FigURE 5(в)

t under: $\left(p_{1} q_{1}+p_{2} q_{2}\right)=80, \tau=0.2$

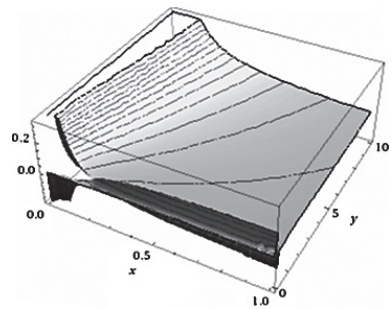

Figure 6(B)

t under: $\left(p_{1} q_{1}+p_{2} q_{2}\right)=80, \tau=0.3$

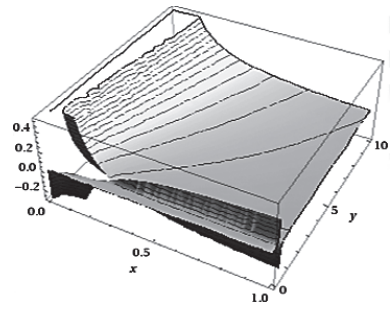

If the figures on the left are compared with those on the right, $t$ decreases considerably as the value of the private sector goods increases, because presumably the tax base increases. Also, comparing the diagrams by rows and columns, we can see that $t$ increases faster in response to increases in $\tau$ as the value of the private goods becomes smaller, because, apparently, of the difference in tax base. Moreover, note that now, there is no optimal locus, the pattern of contours suggesting that 
once they become parallel to each other, a certain public firm size can accommodate the provision of very large quantities of the merit good under a modestly increasing $t$. They also suggest that the same quantities might be provided under a smaller size but at higher $t$ 's. These conclusions are based on the tendency of the parallel contours to be slightly upward sloping starting from some minimum configuration of $t, \omega_{s}$ and $q_{s}$. In sum, ad valorem taxation is more flexible and less antagonizing of the private sector firms relative to revenue neutral specific taxation under consumer sovereignty, but the latter type of excise taxation is more precise in terms of optimality. The difference in optimal private sector size implies that specific taxation induces a private-firm structure prone to realizing economies of scale that are high relative to the case of ad valorem taxation. That is, specific taxation fosters not only consumer sovereignty, but also production efficiency. Given additionally the efficiency under which the public firm is supposed to operate, specific taxation is more compatible with overall Pareto efficiency than $a d$ valorem taxation.

\section{CONCLUDING REMARKS}

There is the possibility that both taxes are associated with the same increase of private goods' output; the specific one, as the result of the tax rate decrease prompted by the increased efficiency of smaller firms after the tax, and the sales tax, because of the tax rate decline induced by higher production capability on the basis of larger post-tax private-firm size vis à vis producer size under the sales tax. There is no way to check this out in the framework of this paper. But if it is true, and both taxes are consistent with overall Pareto efficiency, then, insofar as the financing of merit goods is concerned, the ultimate choice between the two taxes is the institutional attitude towards the size of the private sector. Commodity, in general, taxation has been found here to be welfare enhancing not only because of the macroeconomics of "supply creates its own demand", mentioned in the introductory section and verified more or less by the calibrations, but because also of the analytical context of differentiated oligopoly (Cremer and Thisse, 1994) subsumed by the use of quasi quadratic utility (Choné and Linnemer, 2019). It is also a Lindahl-Foley context, but with respect to complementary goods, verifying the conclusion that a Walrasian equilibrium does exist in quasilinear markets for such goods, too (Azevedo, Weyl and White, 2013). It would still exist under weak Pareto optimality if the preferences for merit goods were assumed to be pathological (as del Mar Racionero (2001) assumes), but coming out of intergenerational altruism (Raut, 2016), given that health and education do hinge upon intergenerational concerns.

Of course, there is a number of critical assumptions behind our results, which need to be rechecked by a broader analytical framework, especially with respect to the choice of utility function, the hypothesis of general complementarity, and the Lindhal-Foley apparatus. For example, all prices here have been conjectural, but the optimum can still be decentralized, and complementarity between merit and non-merit goods can still be possible. Yet this is a feature of the paper that, 
according to Diamantaras, Gilles and Scotchmer (1996), may not hold under different assumptions, unless at least the postulate about general complementarity is relaxed. Moreover, although our Walrasian equilibrium under general complementarity presupposes a largescale economy, having subsequently countrywide relevance, the optimal scale justified by a model setting differing from ours may be the local jurisdiction. Furthermore, although one might contend in view of Levaggi and Menoncin's (2008) findings that our results are robust to the qualification of tax evasion because simply they refer to merit goods provision - qualification making sense if these goods exist already in the economy and consumers choose on the basis of after-tax income - this viewpoint needs to be reassessed. In any case, the comparative statics should have the macro-dynamic character originating in the transition from a pre-merit good status quo to the new equilibrium following the introduction of such a good in the economy.

The bottom line is that the provision of merit goods can serve as an engine of economic growth and development in a free market economy. The paper was not written to support this claim; this thesis merely stemmed from a theoretical argument illustrated through calibrations and motivated by the empirical evidence that these goods and complement private consumption. It is a position stripped of any ethical directives, and is irrelevant conceptually to concerns about the efficiency of public education and/or health provision. After all, health and education are social capital, boosting productivity and growth (Brooks and Nafukho, 2006), conferring at least short- and long-term well-being as well, even if the Easterlin paradox is correct (Bartolini and Sarracino, 2014). Nevertheless, it is a proposition that might complement the quests for merit goods as means of alleviating the income inequality that undermines the system of free enterprise, and of internalizing by the state such psychological externalities as multiple preference orderings and the failure of agents to choose in their own best interests (Mann, 2006).

\section{Disclosure statement}

No potential conflict of interest was reported by the author. 


\section{REFERENCES}

1. Azevedo, E. M., Weyl, E. G. and White, A., 2013. Walrasian equilibrium in large, quasilinear markets. Theoretical Economics, 8(2), pp. 281-290. https:// doi.org/10.3982/te1060

2. Bartolini, S. and Sarracino, F., 2014. Happy for how long? How social capital and economic growth relate to happiness over time. Ecological Economics, 108, pp. 242-256. https://doi.org/10.1016/j.ecolecon.2014.10.004

3. Brooks, K. and Nafukho, F. M., 2006. Human resource development, social capital, emotional intelligence: Any link to productivity? Journal of European Industrial Training, 30(2), pp. 117-128. https://doi.org/10.1108/03090590610651258

4. Chang, M. C., 2000. Rules and levels in the provision of public goods: The role of complementarities between the public good and taxed commodities. International Tax and Public Finance, 7, pp. 83-91.

5. Choné, P. and Linnemer, L., 2019. The quasilinear quadratic utility model: An overview. HAL Id: hal-02318633.

6. Cremer, H. and Thisse, J.-F., 1994. Commodity taxation in differentiated oligopoly. International Economic Review, 35(3), pp. 613-633. https://doi. org/10.2307/2527077

7. Cserne, P. and Desmarais-Tremblay, M., 2018. Merit goods. Forthcoming. In: M. Sellers and S. Kirste, eds. Encyclopedia of the philosophy of law and social philosophy (Springer, 2021). TILEC Discussion Paper, No. DP 2018-008. https://doi.org/10.2139/ssrn.3119566

8. Del Mar Racionero, M., 2001. Optimal tax mix with merit goods. Oxford Economic Papers, 53(4), pp. 628-641. https://doi.org/10.1093/oep/53.4.628

9. Desmarais-Tremblay, M., 2017. Musgrave, Samuelson, and the crystallization of the standard rationale for public goods. History of Political Economy, 49(1), pp. 59-92. https://doi.org/10.1215/00182702-3777158

10. Desmarais-Tremblay, M., 2019. The normative problem of merit goods in perspective. Forum for Social Economics, 48(3), pp. 219-247. https://doi.org/1 0.1080/07360932.2016.1196593

11. Diamantaras, D., Gilles, R. P. and Scotchmer, S., 1996. Decentralization of Pareto optima in economies with public projects, nonessential private goods and convex costs. Economic Theory, 8(3), pp. 555-564. https://doi.org/10.1007/ s001990050105

12. Fiorito, R. and Kollintzas, T., 2004. Public goods, merit goods, and the relation between private and government consumption. European Economic Review, 48(6), pp. 1367-1398. https://doi.org/10.1016/j.euroecorev.2004.01.004

13. Florenzano, M. and del Mercato, E. L., 2006. Edgeworth and Lindahl-Foley equilibria of a general equilibrium model with private provision of pure public goods. Journal of Public Economic Theory, 8(5), pp. 713-740. https://doi. org/10.1111/j.1467-9779.2006.00285.x

14. Foley, D., 1970. Lindahl's solution and the core of an economy with public goods. Econometrica, 38, pp. 66-72. https://doi.org/10.2307/1909241 
15. Groot, W. and van den Brink, H. M., 2006. What does education do to our health? In: Measuring the effects of education on health and civic engagement: Proceedings of the Copenhagen Symposium, ch. 4, pp. 355-363.

16. Kaufman, H., 1998. Topics in Public Economics: Theoretical and Applied Analysis. Cambridge, AK: Cambridge University Press.

17. Kotera, G. and Sakai, S., 2017. Complementarity between merit goods and private consumption: Evidence from estimated DSGE model for Japan. KIER Discussion Paper, No. 978.

18. Levaggi, R. and Menoncin, F., 2008. A note on optimal tax evasion in the presence of merit goods. Economics Bulletin, 8(7), pp. 1-13. https://doi.org/10.2139/ ssrn. 979687

19. Mann, S., 2006. Merit goods in a utilitarian framework. Review of Political Economy, 18(4), pp. 509-520. https://doi.org/10.1080/09538250600915691

20. Raut, L. K., 2016. Two-sided altruism, Lindahl equilibrium, and Pareto optimality in overlapping generations models. Economic Theory, 27, pp. 729736. https://doi.org/10.1007/s00199-004-0562-9

21. Schroyen, F., 2005. An alternative way to model merit good arguments. Journal of Public Economics, 89(5-6), pp. 957-966. https://doi.org/10.1016/j.jpubeco.2004.05.006

22. Shubik, M. and Levitan, R. E., 1980. Market Structure and Behavior. Cambridge MA: Harvard University Press.

23. Wenzel, H. and Wiegard, W., 2006. Merit goods and second-best taxation. Public Finance $=$ Finances publiques, 36, pp. 125-140. 
The results from Figs. 2 and 3, appear to be at variance with the intuition that $d \omega /$ $d \beta<0$, coming out of the total differential: $d\left(\partial^{2} \Gamma / \partial q^{2}\right)$. The reason is, certainly, the presence now of $\tau$. Solving (8) for $\omega_{s}$, and differentiating with respect to $\beta$, yields that:

$$
\left.\frac{\partial \omega_{s}}{\partial \beta}=-\frac{\tau^{2} q_{s}^{2}(1-\sigma)\left(a_{s} q_{s}-1\right)}{\left[\tau\left(\beta a_{s} q_{s}-\beta-\sigma q_{s}^{2}\right)-\sigma q_{s}\right]^{2}}\right\} \begin{aligned}
& >0 \text { iff }\left(a_{s} q_{s}-1\right)<0 \\
& <0 \text { iff }\left(a_{s} q_{s}-1\right)>0
\end{aligned}
$$

The calibrations assume that $\left(a_{s} q_{s}-1\right)>0$, and the sign of the derivative: $d \omega / d \beta$ appears that it should "continue" being negative. But, note that:

$$
\left.\frac{\partial \omega_{s}}{\partial q_{s}}=\frac{\tau q_{s}\left(\tau \beta a_{s} q_{s}-2 \beta \tau-\sigma q_{s}\right)}{\left[\tau\left(\beta a_{s} q_{s}-\beta-\sigma q_{s}^{2}\right)-\sigma q_{s}\right]^{2}}\right\} \begin{aligned}
& 0 \text { iff } \tau>\sigma q_{s} /\left[\beta\left(a_{s} q_{s}-2\right)\right] \\
& <0 \text { iff } \tau<\sigma q_{s} /\left[\beta\left(a_{s} q_{s}-2\right)\right]
\end{aligned}
$$

which in our calibrations holds with the positive sign, because $\left(a_{s} q_{s}-2\right)>0$ has been postulated, too. Now, letting all expressions below incorporate the assumption that $\sigma<0: \partial \omega_{s} / \partial \mathrm{q}_{s}>\left|\partial \omega_{s} / \partial \beta\right|$ iff:

$$
\tau>\frac{\sigma q_{s}}{\left[q_{s}(1+\sigma)\left(a_{s} q_{s}-1\right)-\beta\left(a_{s} q_{s}-2\right)\right]}
$$

which is true, because if the result: $d \sigma / d \beta<0$, which obtains in connection with: $d\left(\partial^{2} \Gamma / \partial q^{2}\right)$, is to continue holding in the presence of taxation, the denominator of:

$$
\frac{\partial \sigma}{\partial \beta}=-\frac{\tau^{2} q_{s}^{2}(1+\sigma)\left(a_{s} q_{s}-1\right)}{\tau q_{s}^{2}\left[q_{s}\left(\tau q_{s}-2 \tau \sigma-1\right)-\beta \tau\left(a_{s} q_{s}-1\right)\right]}
$$

has to be positive, given a positive numerator, implying, in turn, that:

$$
\tau>\frac{q_{s}}{q_{s}\left(q_{s}-2 \sigma\right)-\beta\left(a_{s} q_{s}-1\right)}
$$

and hence:

$$
\begin{gathered}
\tau>\frac{q_{s}}{q_{s}\left(q_{s}-2 \sigma\right)-\beta\left(a_{s} q_{s}-1\right)}>\tau>\frac{\sigma q_{s}}{\left[q_{s}(1+\sigma)\left(a_{s} q_{s}-1\right)-\beta\left(a_{s} q_{s}-2\right)\right]} \Rightarrow \\
\left(a_{s} q_{s}-1\right)\left[q_{s}(1+\sigma)-\sigma \beta\right]>\sigma q_{s}\left(q_{s}-2 \sigma\right)+\beta\left(a_{s} q_{s}-2\right)
\end{gathered}
$$

which is also true given the values chosen for the calibrations. Also, since, $\tau>q_{s} /\left[q_{s}\left(q_{s}-2 \sigma\right)-\beta\left(a_{s} q_{s}-1\right)\right]$ :

$$
\frac{\partial \omega_{s}}{\partial \sigma}=\frac{\tau q_{s}^{2}\left[q_{s}\left(\tau q_{s}-2 \tau \sigma-1\right)-\beta \tau\left(a_{s} q_{s}-1\right)\right]}{\left[\tau\left(\beta a_{s} q_{s}-\beta+\sigma q_{s}^{2}\right)+\sigma q_{s}\right]^{2}}>0
$$


Moreover, continuing to incorporate in the expressions that $\sigma<0$ :

$$
\frac{\partial \omega_{s}}{\partial \tau}=\frac{(1-\sigma) q_{s}^{3} \sigma}{\left[\tau\left(\beta a_{s} q_{s}-\beta+\sigma q_{s}^{2}\right)+\sigma q_{s}\right]^{2}}>0
$$

and, we have the total differential:

$$
d \omega_{s}=\frac{\partial \omega_{s}}{\partial q_{s}} d q_{s}+\frac{\partial \omega_{s}}{\partial \sigma} d \sigma+\frac{\partial \omega_{s}}{\partial \tau} d \tau-\frac{\partial \omega_{s}}{\partial \beta} d \beta
$$

The results from the calibration reflect this algebra. They are plausible because according to Fig. 1, there cannot be that: $\left(a_{s} q_{s}-1\right)<0$, and because they are not influenced by the scale of $q_{s} \equiv y$. 